\title{
A Perspective of Evolution for Carbon Emissions Trading Market: The Dilemma between Market Scale and Government Regulation
}

\author{
Qi Zhu \\ The College of Finance and Statistics, Hunan University, Changsha, China \\ Correspondence should be addressed to Qi Zhu; zhuqi@hnu.edu.cn
}

Received 4 November 2016; Revised 20 December 2016; Accepted 4 January 2017; Published 1 February 2017

Academic Editor: Fazlollah Soleymani

Copyright ( 2017 Qi Zhu. This is an open access article distributed under the Creative Commons Attribution License, which permits unrestricted use, distribution, and reproduction in any medium, provided the original work is properly cited.

\begin{abstract}
Which means are more effective for reducing carbon emission? Our paper argues the effect of the government regulation and the market trading on the carbon emission. Based on our model, we obtain three conclusions as follows. First, government strengthened regulation can encourage firms to participate in the trading market for carbon emission. Second, there is the negative relation of supervision cost to trading price. Third, there is an alternative relationship between the scale economy level of the supervisory authority and that of the carbon emissions market. Meanwhile, our numerical simulations also confirm our results for our model analyses.
\end{abstract}

\section{Introduction}

Developed countries and developing countries are debating the rights and responsibilities for carbon emissions management, making the already difficult global greenhouse gas management more difficult. However, carbon emission management has become a major concern for human development. Developed countries which have established a relatively complete system, such as the United States, Europe, and Japan, have tried to manage carbon emissions by administrative means and market instruments. China, as a developing country, is not compulsively obligated to carbon emission reduction; however, based on Chinese domestic and international environment, it is imperative to take the initiative to assume responsibility for carbon reduction. First, as a responsible big power, China must face the challenge of preventing global warming with international communities; second, China is faced with the task of restructuring the economic structure and optimizing the quality of economic growth. Therefore, establishing a binding carbon emission management mechanism has become a necessity for Chinese development.

The market transaction for carbon emission right is a principal mean for the international carbon emissions management cooperation. Carbon emission right trading is a method countries utilize to meet their obligations specified by the Kyoto Protocol, as signatory nations are committed to achieve a certain carbon emission reduction targets in a certain period of time and then assign it to different domestic enterprises; when one country cannot meet its target on schedule, it can purchase a certain amount of quotas or emission permits from the countries that have the quota or emission permit (mainly developing countries) to meet their own emission reduction targets. Similarly, within a country, companies can also do the trading to meet their own targets. According to the Kyoto Protocol, the international greenhouse gas emissions trading system consists of three flexible emission reduction mechanisms (CDM, IET, and JI).

The study of carbon emissions trading can be traced back to scholars' research on emission rights, which is essentially the externality discussion for public goods usage. As public goods, atmospheric pollution is not counted or included in private costs, which suggests that social marginal cost is not consistent with private marginal cost, which leads to market malfunction. In other words, it is difficult for the market to define the property rights of the atmospheric environment, and it loses the function of resource allocation adjustment. In this case, there are two coping strategies in the academic 
research: Pigou Tax (Pigou, 1952) and Coase's Property rights (Coase, 1960).

The practice of emission rights is to use Coase's externality bargaining mechanism (Coase, 1960). Crocker [1] and Dales (1968), respectively, put forward the idea of allocating pollution burdens among market players with tradable permits. Montgomery [2] demonstrated in theory that a tradable permitting system provides an effective public economic policy tool for constraining pollution. After that, scholars began to conduct detailed studies in emissions trading transactions.

In the literatures, both the government and the market are viewed as the important roles of carbon emissions trading market. Government regulation, in the carbon emission management, is essentially compulsory third-party contract enforcement. Barzel [3] argues that one believes that when the value of the investment will be negative, it is less likely that the agreement will be self-enforcing and more parties can benefit from third-party enforcement. At the same time, Barzel (2003), while studying the behavioral game of coercing third party and supervised parties, points out that when the right to cohesive mechanisms of collective action is scaled up and exceeds that of coercive third party of the power, it can also effectively suppress the rights of mandatory third parties. As for the result analysis of government control, Stigler [4] and Peltzman (1976) believe that government regulation only results in the redistribution of resources, rather than the overall output and price. About government control on environment issues, Bettney and Stevens (2003) point out that how to choose a supervisory strategy for the implementation status of environmental standards (i.e., how much economic penalties can be relied upon to restrain violations and the relative advantages and disadvantages of civil liability and criminal penalty) is the difficulty in actual implementation.

Proponents of market-based approaches, however, believe that government control of pollution is aimed at forcing each firm to assume the same share of the burden of pollution control. Regardless of the corresponding cost differentials, although it can effectively control corporate emissions, they also force companies to take unduly expensive pollution control measures, which brings huge costs in the process, while the control also tends to hinder the progress of emission reduction technology (Stavins, 2003; [5]). Downing and White [6], Malueg [7], Milliman and Prince (1989), and Jung et al. [8], respectively, did theoretical analysis on dynamic incentive of sewage behavior under different policy conditions and concluded that marketbased policy management tools with subject of emissions trading are able to motivate polluters to obtain benefits through technological innovation or using more advanced pollutant emission technologies, compared with regulatory actions. Hahn and Noll [9], by analyzing the operating conditions of the emission permit system to reflect on the effect of government regulation, think that the government's penalties for violating the permit system must exceed the cost of purchasing permits in order to encourage producers to adhere to market rules.

More governments have accepted treaties which regulate carbon emission [10]. The cap-and-trade system is one of the most important regulations for carbon emission, and
Li et al. [11] indicate that this system is the most effective method of regulating carbon emission. Under the cap-andtrade system, firms' carbon emissions must meet their rights, and they could also sell or buy carbon rights to meet their emissions. Because purchase and selling of carbon emission rights can affect the production cost, accounting standard setters argue that firms should disclose and report their carbon liabilities [12]. Besides, capital investment in manufacture or production industry is affected by carbon emission costs [13]. It is acknowledged that compliance with any emission regulation would probably increase firms' costs [10]. And Clarkson et al. (2015) asserted that value of firms whose carbon emissions exceed their rights is abated while value of firms which comply with all the regulations would not be affected by the cap-and-trade system. However, their empirical result also suggested that firms' latent carbon liabilities could be alleviated by their ability of future shifting of costs on carbon emission. Cap-andtrade system also affects other industries; for instance, Li et al. (2015) examined the effect of cap-and-trade system on truck routing, and found that transportation firms try to pursue an equilibrium on which economic cost and carbon emission are balanced under this system. To be more specific, firms try to get a minimum economic cost when carbon is relatively cheap, while trying to get a minimum carbon emission when carbon is extremely expensive. Moreover, other regulations, such as pollution taxes, on carbon emission can make sense. If the elasticity of demand of a certain good is very small, carbon tax could bring a higher return to capital [14].

At the same time, the transaction cost is also an important variable for the decision-making of the government and market actors in the carbon emission trading market. The lawmakers believe that creating a set of rules and regulatory bodies is much less expensive than creating a market or selling sewerage permits (Burges, 1995). However, the government's ability to monitor carbon emissions is also constrained by the level of capacity, and Barzel (2003) argues that the ability to impose costs limits the scope of third-party enforcement. However, with the improvement of the market system, transaction costs will decline, because intermediary organs can reduce financial transaction costs, through the establishment of trading systems to reduce the transaction information asymmetry ( $\mathrm{Da}, 2007)$. Chen [15] believes that market can get the real value for pollution right because of value discovery of trading.

In the carbon emission trading market, government regulation and scale economy of market transactions are indispensable factors in the study of functioning of the carbon trading market; specialization has long been known as the basic factor for the formation of scale economy (William and Joanna, 1997). Lin (2002) considers that there are four forms of scale economy, which from a dynamic point of view, through mass production transactions, making the division of labor more specialized, resulting in scale of income. $\mathrm{Gu}$ (1999) divides scale economy into three levels, in which the first one is the decrease of unit product cost through the expansion of production scale, till the lowest point of average cost. In terms of the scale income of government regulation, 
Barzel (2003) believes that third-party enforcement allows for specialization in the accumulation of enforcement rights.

Based on the perspective of scale economy and transaction costs, our paper uses stochastic dynamic model to analyze the influence of government regulation and market trading on carbon emission. The second section provides a stochastic dynamic model. The third section analyzes the effect of government regulation and trading market on the carbon emission based on stochastic dynamic model. The fourth section provides numerical simulations of our propositions. At last, our paper shows main conclusions and contributions.

\section{Model Setup}

Suppose that the utility of the carbon market is maximized over time, as there are different preferences at each stage of development; assuming there is a subjective discount rate $\rho$, where $\rho>0$, with that, the future welfare can be discounted to the current period. In the planning period $[0,+\infty]$, the welfare function $V$ can be expressed as

$$
V(S, t)=\max \int_{t}^{+\infty} e^{-\rho m} U(S(m), \eta(m)) d m .
$$

Among it, $S$ shows the stock of new carbon emissions in current society, $U(S)$ represents the effect of the carbon stock of new emissions on the utility of mankind. The discount rate $\rho$ reflects the contemporary assessment of the future environment, which is influenced by many factors, including people's expectation of technological development, expectation of economic development level, and people's tolerance to greenhouse gas pollution.

Due to the inconsistency of microcosmic expectation, people choose different carbon emission behaviors at different stages, which lead to the random fluctuation of carbon emission increment $S$; thus, suppose that the changing path of $S$ obeys Brownian motion:

$$
d S=\left(S_{p}-\eta S_{r}\right) d t+\sigma d z, \quad 0<\eta<1
$$

$S_{p}$ represents the current demand of social carbon emissions; $S_{r}$ represents the supply of social carbon emissions in the current period; $\eta$ represents the transaction rate of carbon emissions; $\sigma$ is the degree of risk in the carbon emission system and is assumed to be constant in this paper; $d z$ is a Wiener process defined in a certain probability space, which is called white noise.

The supply of carbon emission rights is mainly composed of two parts, the carbon emission rights sold by carbon emission authority (government) and carbon emissions trading on the market. In a society with strict carbon regulation, the efficiency of carbon emissions trading is often affected by the two forces, namely, the pressure on carbon emissions enterprises under government regulation and legal punishment and the rationalization of carbon emissions trading prices promoted by the expansion of market transactions scale. Suppose the government's regulation probability to a carbon trading firm is $h$, which can also be described as the willingness of individual firms to participate in carbon emissions; then $q=1-h$ reflects the probability that government regulation authorities ignore individual carbonemitting firms; in other words, it is the probability that an enterprise avoids buying the emission permit. $N$ shows the number of participants in the potential carbon trading market as defined by law, that is, the size of potential market transactions. Assuming that an individual firm's violation of the carbon trading rule is an independent event, the probability of the whole firm violating the carbon emissions trading rule is $(1-h)^{N}$. Therefore, this paper assumes that the efficiency of carbon emissions trading market is

$$
\eta=1-(1-h)^{N}
$$

in which $h$ represents the efficiency of carbon emissions regulation and $N$ shows the number of participants in carbon emissions trading market, that is, carbon emissions trading scale.

Assuming that the cost of society as a whole is 1 , let $\tau_{\mu}$ denote the cost of inspection and $\tau_{w}$ the cost of the carbon emissions trading market. Then, the relationship between $\tau_{\mu}$ and $h$ and $\tau_{w}$ and $N$ can be expressed as

$$
\begin{gathered}
\tau_{\mu}^{\varphi_{1}}=\mu h \\
\tau_{w}^{\varphi_{2}}=\omega N,
\end{gathered}
$$

where $\mu$ and $w$, respectively, represent regulatory fees and carbon emissions market transaction costs. $\varphi_{1}$ and $\varphi_{2}$ denote the level of government-regulated and market-oriented economies of scale, respectively.

For the stochastic control model of the carbon emission management system, it essentially controls the change of transaction efficiency $\eta$ in the dimension of time $t$ in order to maximize the social utility. Therefore, it is possible to rewrite (1) as follows:

$$
V(S, t)=\max _{\eta} E_{t} \int_{t}^{+\infty} e^{-\rho m} U(S(m), \eta(m)) d m .
$$

Equation (5) can also be defined as

$$
\begin{gathered}
V\left(S_{0}, t_{0}\right)=\max _{\eta} E \int_{t_{0}}^{+\infty} e^{-\rho m} U(S(m), \eta(m)) d m \\
=\max _{\eta} E\left[\int_{t_{0}}^{t_{0}+\Delta t} e^{-\rho m} U(S(m), \eta(m)) d m\right. \\
\left.+\int_{t_{0}+\Delta t}^{+\infty} e^{-\rho m} U(S(m), \eta(m)) d m\right]=\max _{\eta} E \\
\cdot\left[e^{-\rho m} U(S, \eta) \Delta t+V\left(t_{0}+\Delta t, S_{0}+\Delta S\right)\right] .
\end{gathered}
$$

We can use Ito's lemma for Taylor expansion applied to $V\left(t_{0}+\Delta t, S_{0}+\Delta S\right)$ at any $\left(t_{0}, S_{0}\right)$ and get

$$
\begin{aligned}
V\left(t_{0}+\Delta t, S_{0}+\Delta S\right)= & V\left(t_{0}, S_{0}\right)+V_{t}\left(t_{0}, S_{0}\right) \Delta t \\
& +V_{s}\left(t_{0}, S_{0}\right) \Delta S+\frac{1}{2} \sigma V_{s s} \Delta S^{2}
\end{aligned}
$$


Substituting (7) into (6), we can get

$$
\begin{aligned}
0= & \max _{\eta}\left[e^{-\rho t} U(S, \eta) \Delta t+V_{t}\left(t_{0}, S_{0}\right) \Delta t\right. \\
& \left.+V_{s}\left(t_{0}, S_{0}\right) \Delta S+\frac{1}{2} \sigma V_{s s} \Delta S^{2}\right] .
\end{aligned}
$$

Substituting (2), we can get

$$
\begin{aligned}
0= & \max _{\eta}\left\{\left[e^{-\rho t} U(S, \eta)+V_{t}\left(t_{0}, S_{0}\right)\right.\right. \\
& \left.\left.+V_{s}\left(t_{0}, S_{0}\right)\left(S_{d}-\eta S_{r}\right)+\frac{1}{2} \sigma V_{s s}\right] \Delta t+V_{s} \sigma \Delta z\right\} .
\end{aligned}
$$

HJB equation is thereby obtained:

$$
\begin{aligned}
0= & \max _{\eta}\left[e^{-\rho t} U(S, \eta)+V_{t}(t, S)+V_{s}(t, S)\left(S_{d}-\eta S_{r}\right)\right. \\
& \left.+\frac{1}{2} \sigma V_{s s}\right] .
\end{aligned}
$$

That is,

$$
\begin{aligned}
& -V_{t}(t, S) \\
& =\max _{\eta}\left[e^{-\rho t} U(S, \eta)+V_{S}(t, S)\left(S_{d}-\eta S_{r}\right)+\frac{1}{2} \sigma V_{S S}\right] .
\end{aligned}
$$

The boundary conditions are as follows:

$$
\begin{aligned}
& V_{t}(t, S)=\max (S(T)-u, 0) \\
& V_{t}(t, 0)=0, \quad \forall 0 \leq t \leq T \\
& V_{t}(t, S)=w, \quad \text { let } S \longrightarrow+\infty \\
& V_{t}(0, S)=u .
\end{aligned}
$$

\section{Main Results}

Based on the optimal carbon emissions trading efficiency $\eta^{0}$, with comparative static analysis on the variables in the carbon emissions trading system, the mutual influence relationship between the carbon emissions trading system variables is studied, and the following propositions are obtained.

Proposition 1. With the expansion of the carbon trading market, the probability for supervision increases, but the regulation is marginally diminishing.

From HJB equation, we can get

$$
\begin{aligned}
-V \eta & =e^{-\rho t} U \eta-V_{s} S_{r} \\
\eta_{h} & =N(1-h)^{N-1} \\
\eta_{N} & =-(1-h)^{N} \ln (1-h) \\
\frac{\partial N}{\partial h} & =-\frac{N}{(1-h) \ln (1-h)}>0 \\
\frac{\partial^{2} N}{\partial h \partial h} & =N \frac{1+\ln (1-h)}{(1-h)^{2} \ln ^{2}(1-h)} .
\end{aligned}
$$

Thus, from (15), we can see that when $h>1-1 / e$, $\partial^{2} N / \partial h \partial h<0$, and when $h<1-1 / e, \partial^{2} N / \partial h \partial h>0$.

Equation (14) shows that $h$, the inspection strength of carbon emissions regulation authorities, and $N$, carbon emissions trading market size, vary in the same direction. As $N$, carbon emissions trading market size, expands, the rentseeking income of the supervisory organs has increased, making supervisory authority increase their inspection efforts to obtain inspection proceeds. However, from (15), we can see that there is a critical value of $1-1 / e$; when $h<1-1 / e, h$ is accelerated to increase along with the expansion of market scale $(N)$, and when $h>1-1 / e, h$ is slowed down to increase along with the expansion of market scale $(N)$. This indicates that the regulation cost will gradually restrict the behavior of the supervisory organ, with the expansion of the carbon emissions market to a certain degree; the regulation intention will therefore decline.

Proposition 2. There is the negative relation of supervision cost to trading price. However, increase of regulation cost is faster than trading price for carbon emission right.

From (4), we can get

$$
\begin{gathered}
h_{\mu}=-\frac{1}{\mu^{2}} \tau_{\mu}^{\varphi_{1}}<0 \\
N_{\omega}=-\frac{1}{\omega^{2}} \tau_{\omega}^{\varphi_{2}}<0 .
\end{gathered}
$$

From HJB equation, we can get

$$
\begin{aligned}
& \frac{\partial V}{\partial \mu}=-\left(e^{-\rho t} U_{\eta}-V_{s} S_{r}\right) N(1-h)^{N-1} \frac{1}{\mu^{2}} \tau_{\mu}^{\varphi_{1}} \\
& \frac{\partial V}{\partial \mu}=-\left(e^{-\rho t} U_{\eta}-V_{s} S_{r}\right)(1-h)^{N} \ln (1-h) .
\end{aligned}
$$

Then

$$
\begin{aligned}
\frac{\partial \omega}{\partial \mu} & =-\frac{N\left(1 / \mu^{2}\right) \tau_{\mu}^{\varphi_{1}}}{(1-h) \ln (1-h)}>0 \\
\frac{\partial^{2} \omega}{\partial \mu \partial \mu} & =\frac{2 N\left(1 / \mu^{3}\right) \tau_{\mu}^{\varphi_{1}}}{(1-h) \ln (1-h)}<0 .
\end{aligned}
$$

Equation (16) indicates that, with the enlargement of carbon trading market, the number of competitors in the market increases, the market is gradually approaching a competitive market, emission reduction technology and emission reduction quota are gradually standardized, and the transaction cost of the market decreases. From (17) we can see that the increase in carbon inspection costs will increase the regulation cost, decreasing the regulation intention.

From (19) we can see that the cost of carbon emission inspection and transaction costs change in the same direction; however, the transaction costs change faster. It indicates that there is no competition in regulation market of carbon emissions. With monopoly of government regulation, the inspection costs are rigid, less sensitive, and slower in 
adjustment. But in the carbon emissions market, changes in transaction costs will promptly stimulate market players to adjust carbon emissions (through the market to complete the task of carbon emission reduction, or use their own technology or to cut production or even avoid regulation to complete the task of emission reduction), affecting carbon emissions trading market participation, which will further affect the carbon emissions trading market costs.

Proposition 3. There is an alternative relationship between the scale economy level of the supervisory authority and that of the carbon emissions market, and there is a phenomenon of accelerated substitution.

$$
\begin{aligned}
& \eta_{\varphi_{1}}=N(1-h)^{N} h \ln \tau_{\omega} \\
& \eta_{\varphi_{2}}=N(1-h)^{N} h \ln \tau_{\mu} \\
& \frac{\partial V}{\partial \varphi_{1}}=\left(e^{-\rho t} U \eta-V_{S} S_{r}\right) N(1-h)^{N} h \ln \tau_{\omega} \\
& \frac{\partial V}{\partial \varphi_{2}}=\left(e^{-\rho t} U \eta-V_{S} S_{r}\right) N(1-h)^{N} \ln (1-h) \ln \tau_{\mu} \\
& \frac{\partial \varphi_{2}}{\partial \varphi_{1}}=\frac{h}{\ln (1-h)} \frac{\ln \tau_{\omega}}{\ln \tau_{\mu}}<0 \\
& \frac{\partial^{2} \varphi_{2}}{\partial \varphi_{1} \partial \varphi_{1}}=\left[\frac{1}{\ln (1-h)}-h(1-h)\right] h \ln \tau_{\omega}>0 .
\end{aligned}
$$

Equation (21) shows that the scale economy of carbon emissions regulation is negatively related to that of the carbon emissions trading market; that is, when scale economy increases in the carbon emissions trading market, the scale economy of the supervisory authority declines and vice versa. This indicates that the expansion of the carbon emission trading market will reduce the transaction costs and attract the enterprises to complete the emission reduction task through the transaction, reducing the motive of enterprises to evade regulation or take illegal actions; thus the scale economy of the supervisory organs will be reduced.

From (22), we can see that the increase of scale economy of carbon emission trading market will lead to the accelerated decrease of scale economy of regulation organs. As mentioned above, there is an alternative relationship between the scale economy of the supervisory authority and that of the trading market; meanwhile, specialization also encourages the trading for carbon emissions, so that the scale economy for carbon emissions market is enhanced; if above setting, the cost for transaction will be reduced; the welfare of carbon emissions demand and supply enterprises is therefore increased, encouraging more companies to fulfill legal obligations through carbon trading rather than by evading the regulation, which tends to gradually reduce the effect of regulation authority and accelerate the decline of its scale economy.

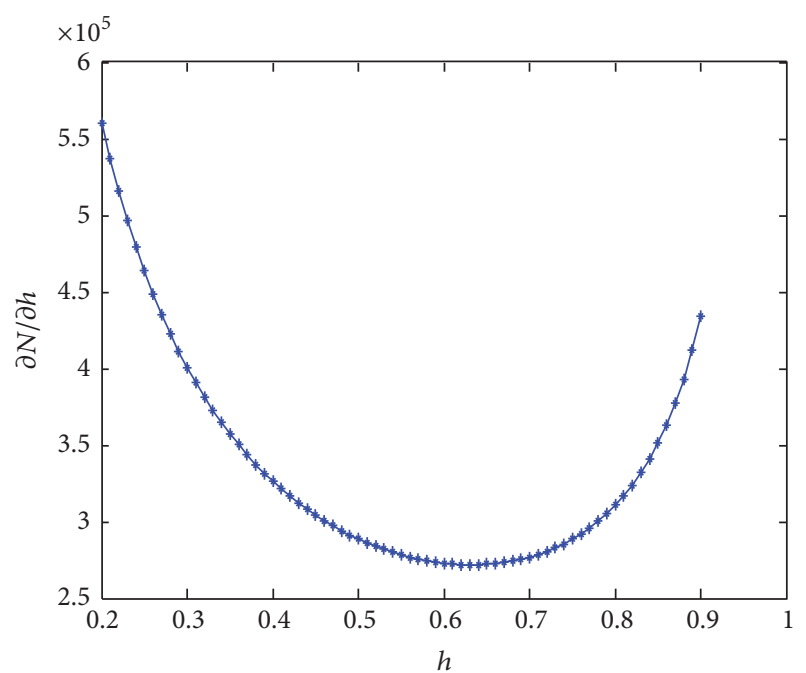

FIGURE 1: The relation between market size and supervision probability with $N=100000 ; h=(0.2,0.9)$.

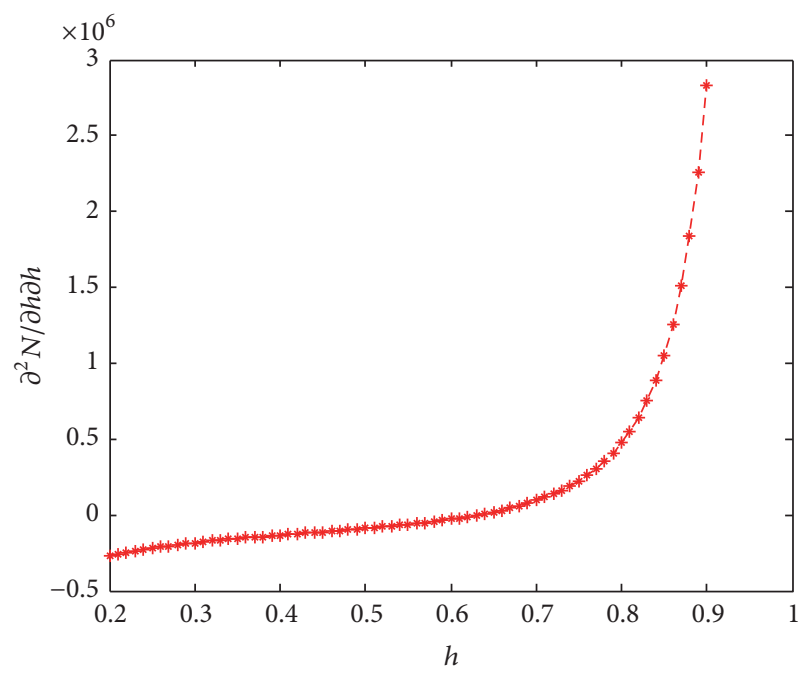

FIGURE 2: The change rate for the relation between market size and supervision probability with $N=100000, h=(0.2,0.9)$.

\section{Numerical Simulation}

In our paper, our models are stochastic and our propositions are embodied by function which still are not intuitional. In this section, based on the MATLAB software, we furtherly use simulation to illustrate the relation between carbon emissions trading market and government regulation.

In Figure 1, we present numerical simulation for the relation between the market size and supervision strength. There is the positive effect of supervision strength on the market size, suggesting that as government strengthens the supervision for carbon emission, firms have incentive to meet regulation condition by the trading market of carbon emission. Meanwhile when $h=1-1 / e$, the incentive for firms to trade carbon emission right is stronger. The above results are confirmed by Figure 2 . 


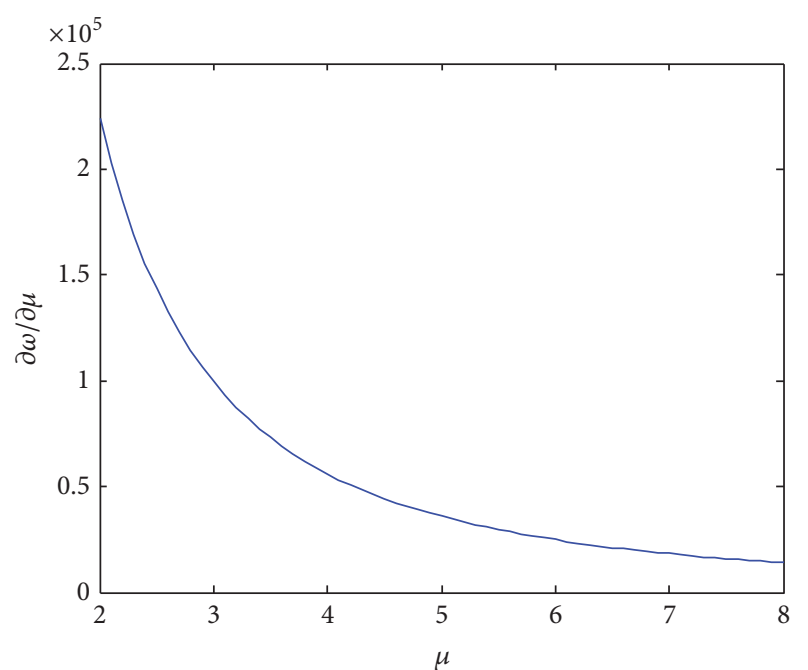

FIGURE 3: The relation between supervision cost and the price for carbon emission right with $N=100000 ; h=0.7 ; \tau_{\mu}=5 ; \varphi_{1}=0.5$; $u=(2,8)$.

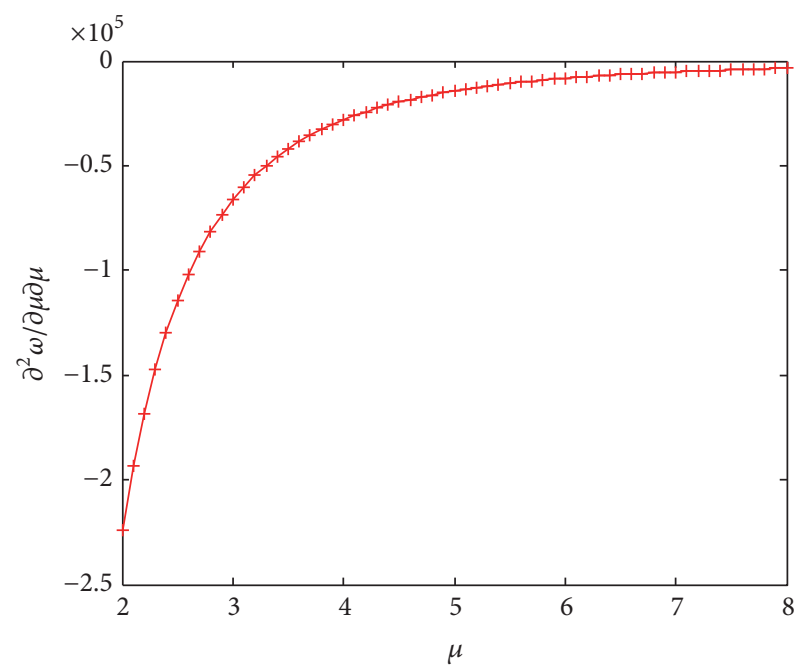

FIgURE 4: The change rate for the relation between supervision cost and the price for carbon emission right with $N=100000 ; h=0.7$; $\tau_{\mu}=5 ; \varphi_{1}=0.5 ; u=(2,8)$.

Figure 3 reports the results for the numerical simulation about the relation between supervision cost and trading price for carbon emission right. There is the negative relation of supervision cost to trading price. These results suggest that, with low supervision cost, government has potential incentive to raise the probability for regulation. Thus, firms are more eager to trade the carbon emission right, so that trading price for carbon emission right rises. However, the increase of regulation cost is faster than trading price for carbon emission right, as in Figure 4. Therefore, firms have potential incentive to participate in the trading market of carbon emission right.

Figure 5 reports that the relation of scale economy for regulation and trading market. In accordance with results

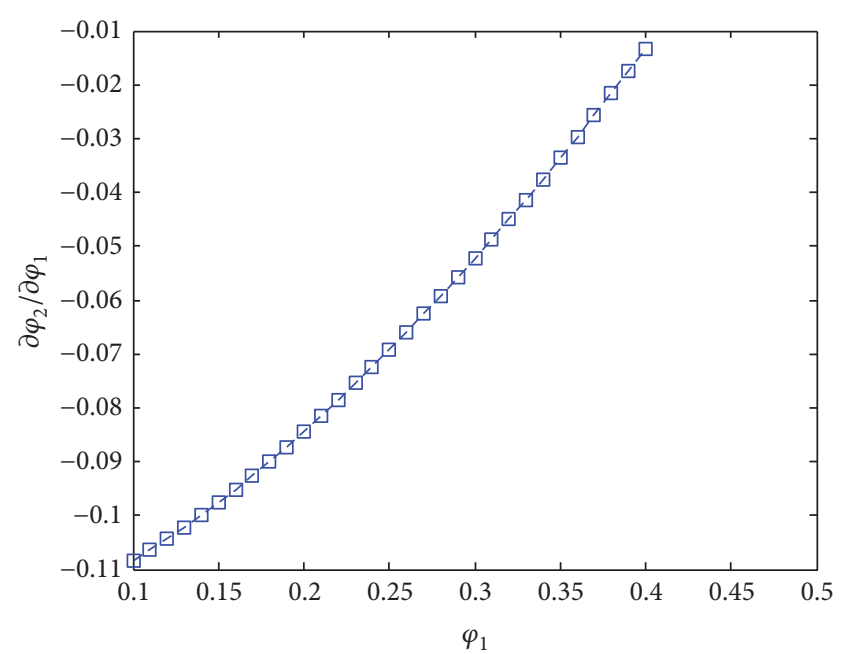

FIGURE 5: The relation of scale economy for regulation and trading market with $u=5 ; \tau_{\mu}=5 ; \tau_{w}=3 ; \varphi_{1}=(0.1,0.4)$.

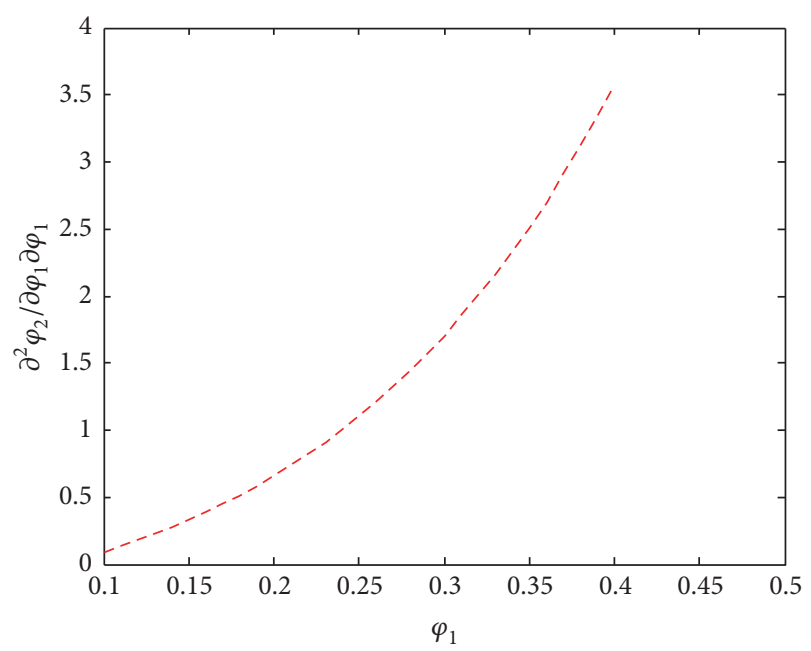

FIgURE 6: The change rate for the relation of scale economy for regulation and trading market with $u=5 ; \tau_{\mu}=5 ; \tau_{w}=3$; $\varphi_{1}=(0.1,0.4)$.

of the numerical simulation, there is the negative relation between the scale economy of regulation and the scale economy of trading market. Meanwhile, in accordance with Figure 6, the scale economy of regulation is restrained when the market of carbon emission right is growing. These results suggest that if the market of carbon emission right is growing, firms are likely to make use of market to reduce the carbon emission.

\section{Conclusion}

Our paper argues the relation between regulation and trading market for carbon emission. our model and the numerical simulation obtain three conclusions as follows. First, government strengthened regulation can encourage firms to participate in the trading market for carbon emission. 
Second, there is the negative relation of supervision cost to trading price. However, increase of regulation cost is faster than trading price for carbon emission right. Third, there is an alternative relationship between the scale economy level of the supervisory authority and that of the carbon emissions market, and there is a phenomenon of accelerated substitution.

Our findings extend the understanding of the market for carbon emission right. Though the regulation and trading market are two parts of reducing carbon emission, they play different role of development for carbon emissions trading market. At initial development stage, the regulation plays more important role in reducing carbon emission. However, if government expects reducing carbon emission by low cost, the development of carbon emissions trading market maybe the only option.

\section{Competing Interests}

The author declares that there is no conflict of interests regarding the publication of this paper.

\section{References}

[1] T. D. Crocker, "The structuring of atmospheric pollution control systems," Economics of Air Pollution, vol. 29, no. 2, p. 288, 1966.

[2] W. D. Montgomery, "Markets in licenses and efficient pollution control programs," Journal of Economic Theory, vol. 5, no. 3, pp. 395-418, 1972.

[3] Y. Barzel, Property Rights and the Evolution of the State. Conflict and Governance, Springer, Berlin, Germany, 2003.

[4] G. J. Stigler, "The theory of economic regulation," The Bell Journal of Economics and Management Science, vol. 2, no. 1, pp. 3-21, 1971.

[5] G. E. Helfand, "Erratum: standards versus standards: the effects of different pollution restrictions," American Economic Review, vol. 81, no. 3, pp. 622-634, 1991.

[6] P. B. Downing and L. J. White, "Innovation in pollution control," Journal of Environmental Economics and Management, vol. 13, no. 1, pp. 18-29, 1986.

[7] D. A. Malueg, "Emission credit trading and the incentive to adopt new pollution abatement technology," Journal of Environmental Economics and Management, vol. 16, no. 1, pp. 52-57, 1989.

[8] C. Jung, K. Krutilla, and R. Boyd, "Incentives for advanced pollution abatement technology at the industry level: an evaluation of policy alternatives," Journal of Environmental Economics \& Management, vol. 30, no. 1, pp. 95-111, 1996.

[9] R. W. Hahn and R. G. Noll, "Environmental markets in the year 2000," Journal of Risk \& Uncertainty, vol. 3, no. 4, pp. 351-367, 1990.

[10] P. M. Clarkson, Y. Li, M. Pinnuck, and G. D. Richardson, "The valuation relevance of greenhouse gas emissions under the European Union carbon emissions trading scheme," European Accounting Review, vol. 24, no. 3, pp. 551-580, 2015.

[11] J. Li, Q. Lu, and P. Fu, "Carbon footprint management of road freight transport under the carbon emission trading mechanism," Mathematical Problems in Engineering, vol. 2015, Article ID 814527, 13 pages, 2015.
[12] Y. Ertimur, J. Francis, A. Gonzales et al., "Credibility, commitment and voluntary environmental disclosures," Working Paper, Duke University, 2010.

[13] B. Sarkar, S. Saren, D. Sinha, and S. Hur, "Effect of unequal lot sizes, variable setup cost, and carbon emission cost in a supply chain model," Mathematical Problems in Engineering, vol. 2015, Article ID 469486, 13 pages, 2015.

[14] D. Fullerton and G. Heutel, "The general equilibrium incidence of environmental taxes," Journal of Public Economics, vol. 91, no. 3-4, pp. 571-591, 2007.

[15] C.-Y. Chen, "Discussion on the orientation of Chinese property right exchange market," Journal of Property Rights, no. 3, 2007. 


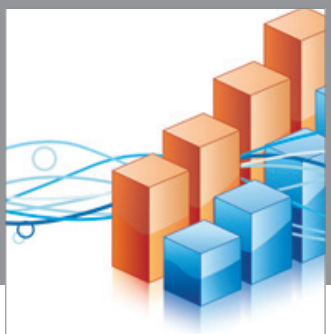

Advances in

Operations Research

vatem alat4

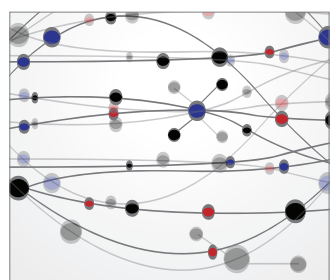

\section{The Scientific} World Journal
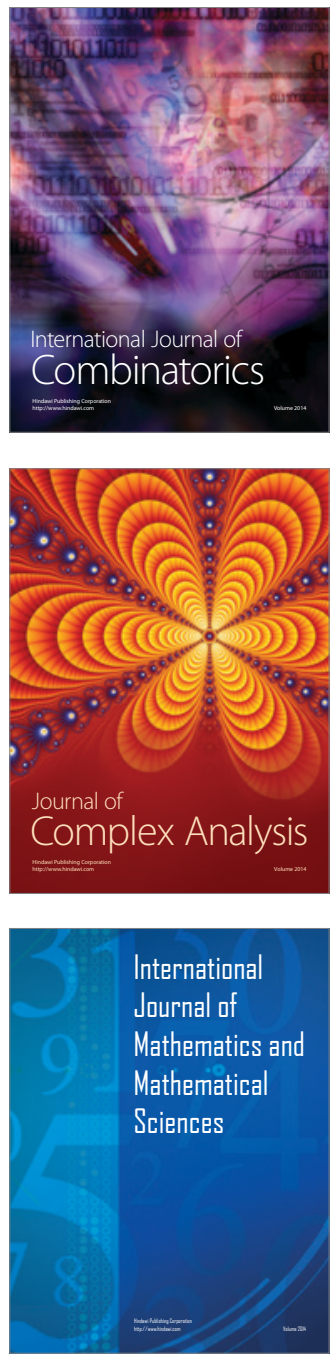
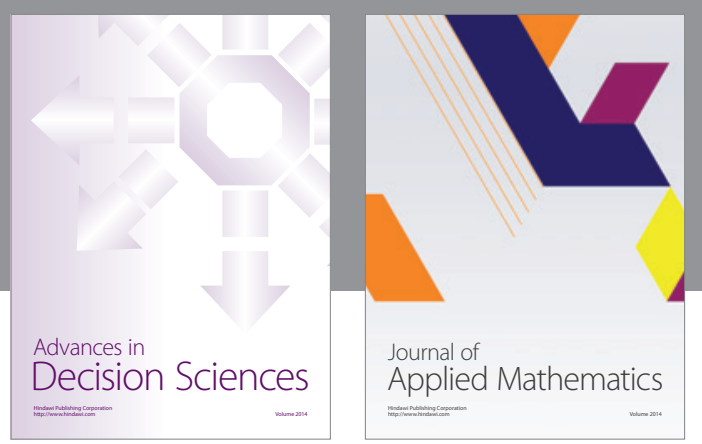

Algebra

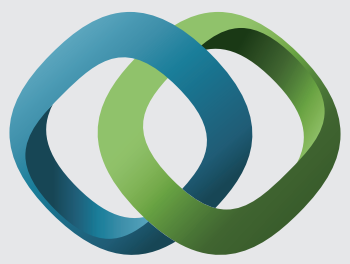

\section{Hindawi}

Submit your manuscripts at

https://www.hindawi.com
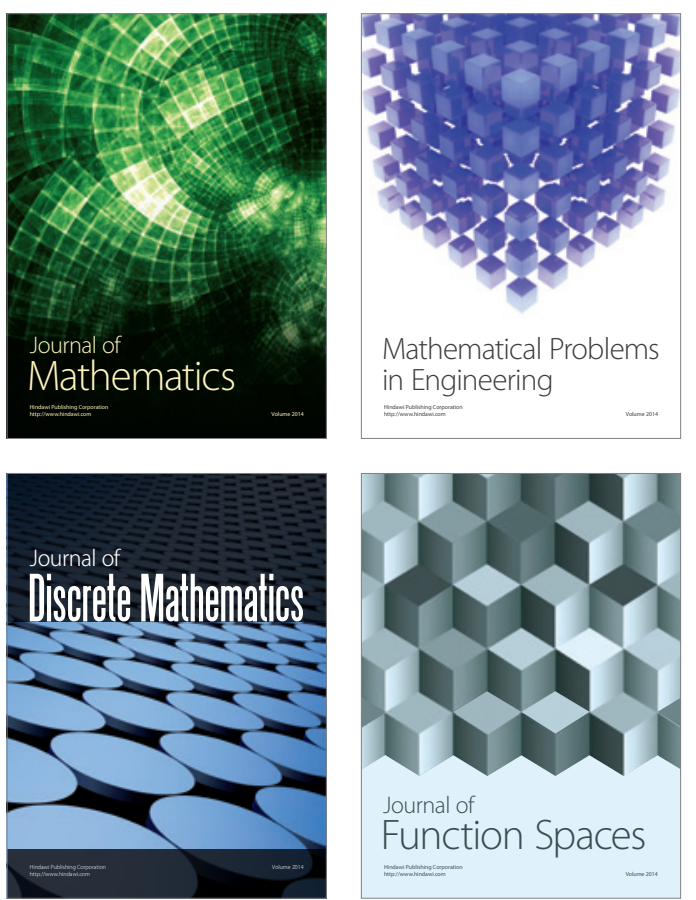

Mathematical Problems in Engineering
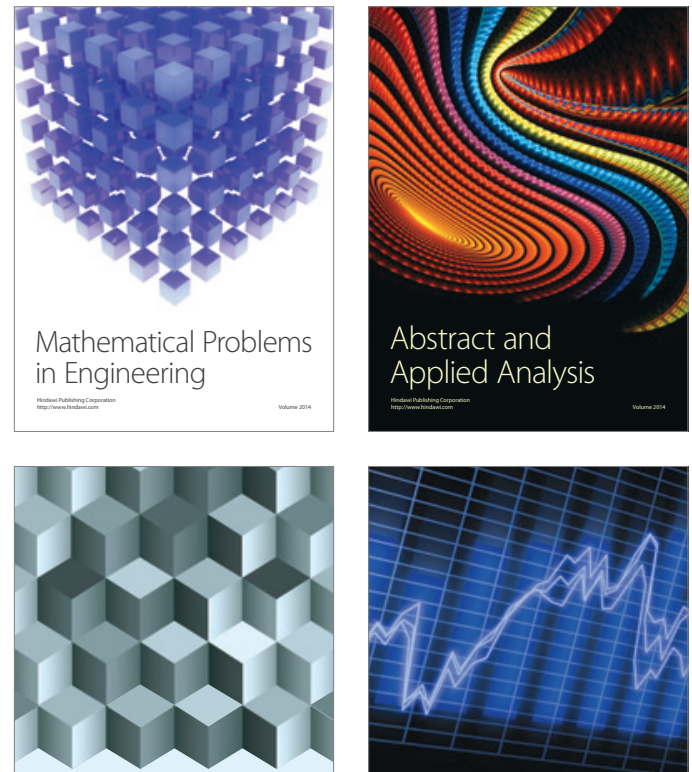

Journal of

Function Spaces

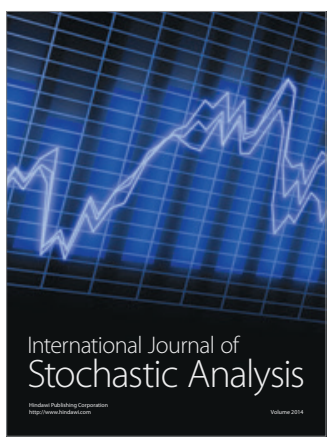

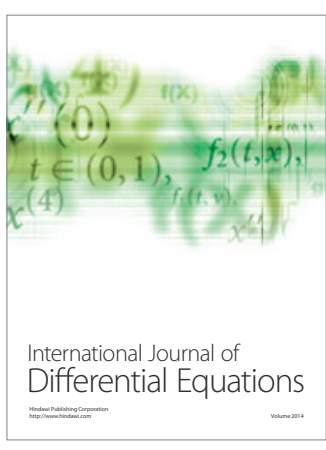
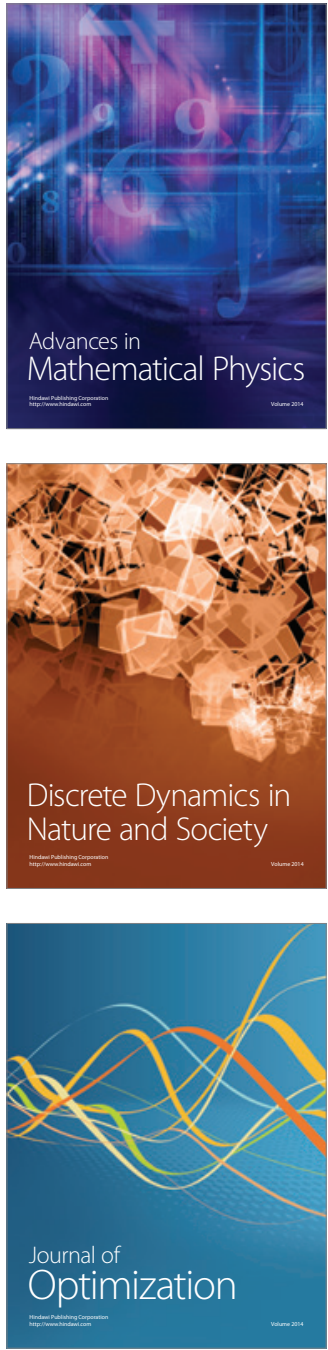